\title{
Distribution of risks and Factors Associated with Unscreened Hypertension among Adults Living in Rural of Dano District, West Shewa, Oromia, Ethiopia, 2020: Community-based cross-sectional study
}

Firaol Regea ( $\nabla$ firaol.regea24.fr@gmail.com )

Assosa University https://orcid.org/0000-0002-6089-9017

\section{Research Article}

Keywords: Unscreened hypertension, Rural Area, Adults, Dano District

Posted Date: July 30th, 2021

DOl: https://doi.org/10.21203/rs.3.rs-762687/v1

License: @ (i) This work is licensed under a Creative Commons Attribution 4.0 International License. Read Full License 


\section{Abstract}

Background: Hypertension affects more than one quarter of adults worldwide and one in three peoples in developing countries. Although Hypertension is known to be a silent medical condition, there is limited information on the prevalence of unscreened hypertension and associated factors among rural dwellers in Ethiopia in general and Dano district in particular.

Objective: To assess the prevalence of Unscreened hypertension and associated factors among adults living in the rural area of Dano district, West Shewa, Oromia, Ethiopia 2020.

Methods and materials - A community-based cross-sectional study was employed. A multi-stage sampling technique was used to select 605 Adults from the rural community of Dano District from May 23 -July 5, 2020. Data were collected by trained BSc nurses and Public health officers. Standardized WHO STEPS survey tool was used to collect socio-demographic and behavioral characteristics of the participants. Standardized digital blood pressure device was used to measure Blood pressure. The mean score of three blood measurements was used to classify hypertension after intra-class correlation was tested. Gmate ${ }^{\mathrm{TM}}$ blood glucose measuring device was used to measure blood sugar. Multivariable logistic regression analysis was done to identify factors independently associated with unscreened hypertension. Adjusted Odds Ratio with $95 \% \mathrm{Cl}$ was estimated to measure the strength of association. The level of statistical significance was declared at $p$-value $<0.05$. The results presented by tables and figures.

Result: The prevalence of Unscreened Hypertension was 14.6\%, (95\% Cl: 11.95\%, 17.4\%). Being in age of 19-33 years[(AOR: $2.5,95 \% \mathrm{Cl}:(1,6)]$, having family history of hypertension [AOR=3.1,95\% Cl: $(1.23,7.77)]$,having other chronic disease [AOR=0.28,95\% Cl:(0.11, 0.72)], Participants' health-seeking behaviour to hypertension[AOR=3.3,95\% Cl:(1.6,6.5)] and participants knowledge about hypertension[AOR=2.3,95\% Cl:(1.2,4.5)]were independently associated with unscreened Hypertension.

Conclusion - The evidence from this study shows unscreened hypertension is prevalent among adults in the study area. Therefore, opportunistic screening of adults regardless of their age and health status is important.

\section{Introduction}

High blood pressure is also known as Hypertension is the leading contributor of cardiovascular related death and disability, which defined as systolic blood pressure $\geq 140 \mathrm{~mm} \mathrm{Hg}$ and/or a diastolic blood pressure $\geq 90 \mathrm{mmHg}(1)$. Hypertension is driven by complex and inter-connected etiologies and damage blood vessels along with organ function which increases the risk of developing several fatal complication including heart attack, stroke, kidney failure, coronary artery disease, cerebrovascular accidents and congestive heart failure(2).

Globally, an estimated 1.13 billion people worldwide have hypertension and two-thirds of them living in low- and middle-income countries(3). Across the WHO region, the prevalence of hypertension in adults 
was ranged from the lowest, $18 \%$ in America to the highest rate, $27 \%$ in the Africa region(4). In Ethiopia, the second highly populated country in Africa, the Ethiopia WHO STEP report of 2015/16 reported the national prevalence of hypertension in the adult population was $16 \%$ (5). Hypertension is responsible for $19 \%$ of global deaths, $45 \%$ of heart disease-related deaths $51 \%$ of stroke-related death, and $3.7 \%$ of total Disability Adjusted Life Years (DALYs) respectively. The global direct medical cost of Hypertension is estimated at 370 billion US\$ per year. On the other hand, effective management could reduce the expenditure to 100 billion US\$ per year $(3,4,6)$.

Hypertension rarely causes symptoms and many people fail to be diagnosed for many years until a serious medical problem occurs. Symptoms that can be associated with hypertension are very generic and cannot necessarily be relied upon to diagnose hypertension and make it unnoticed (7). WHO 2016 reported that, seven (7\%) of global Cardiovascular diseases including Hypertension are delayed in screening and diagnoses which caused by limited access to health care service due to lack of money, health information, remoteness, illiteracy, travel constraints and a limited number of health care facilities (8).

Early treatment of hypertension has been documented as having beneficial effects to decrease the risk of morbidity and mortality due to its complication and the identification of Unscreened status with its associated factors is important to determine public health priorities(1). However, due to its nature of silence, it might be left undiagnosed until serious complications occurred. Ethiopia, WHO NCD STEP report 2015/2016, revealed that majority (79.9\%) of rural Ethiopia had not ever screened for their blood pressure.

In spite of the potential importance of uncovering the hidden magnitude of hypertension, a little information was available about unscreened hypertension among adults living in rural areas in Ethiopia in general and Dano district in particular. Current study assessed the prevalence and the relative effects of sociodemographic, socioeconomic, behavioral and life style, personal and health seeking behavior, and psychosocial hypertension screening. Therefore, the purpose of this study was to assess the prevalence and associated factors of unscreened hypertension among adults of rural dwellers.

\section{Methods And Materials}

Study area and Design- Community based cross-sectional study design was conducted from May 23 July 5, 2020, in Dano district, West Shewa, Oromia, Ethiopia. Dano district is located 225 Kilometer to the west of Addis Ababa, the capital city of Ethiopia and Seyo is its major town. The 2017 Ethiopian census projection reported a total population of Dano district is 122,618 of whom and 60,706 and 61,912 were Men and women respectively. Dano District has 27 Gandas (The small administrative unit),five urban administration and 23 rural Gandas(11).

Population and sample size - Those Adults aged 19 to 65 years living in the rural areas Dano district were included in the study whereas, those Adults who were previously diagnosed with hypertension, those screened for hypertension in the last year, pregnant mothers and mothers in post-partum periods were 
excluded from the study. A multi-stage sampling technique was used to select the study participants. Stage one; selecting representative Gandas; seven rural Gandas were randomly selected by the lottery method from 23 rural Gandas of Dano district. Stage two, selecting eligible individuals; those eligible individuals were enumerated and registered to get a complete frame of the study population among randomly selected Gandas. In order to get those eligible individuals during data collection easily, the corresponding individual household was coded and registered in lining with their name. Stage three, the total sample size was allocated by probability proportional to size to each Ganda based on the number of eligible individuals they have. Then finally, 605 adults were selected using computer generated Lottery method based on the determined proportion of each Ganda's.

Data collection tools and procedure - Participants information on Socio-demographic variables behavioral and life style, physical measurement and biochemical measurement( blood glucose level) was collected using standardized WHO STEPS wise approach V.3.2(12) tool that designed for surveillance of non-communicable disease. Participants health seeking behaviour was assessed using questionnaire adopted from health belief model $(13,14)$ and participants knowledge was assessed using a questionnaire which was adapted from Hypertension Knowledge-Level Scale (HK-LS) after reliability assessed for reliability (15).

The questionnaire that was developed in the English language was translated to Afan Oromo and return back to the English language to see for the consistency of both the English and Afan Oromo version of the questionnaire.

At first glance, eligible adults were enumerated; their corresponding households were coded and registered in lining with the individuals' name by health extension workers. Secondly, Data were collected by healthcare professionals holding at least BSC degree in nursing and public health officer after intensive training was given on the objectives of the study, STEPS survey procedures, and tools. A pre-test of the structured questionnaire was conducted before the actual data collection on in adjacent Ganda, that was not included in the study to check for the validity of the instruments and then necessary corrections were made. Blood pressure was measured using, Riester ri-champion $\circledast N$, automated and clinically validated (to the British Society for hematology standard). The participants were asked to rest (relax) with setting on the chair; legs uncrossed, feet on the floor, back supported and insured empty bladder, no smoking, exercise coffee/tea 30 minutes before measurement. Device integrity was checked and disinfected using 70\% Isopropyl Alcohol to protect them from COVID-19. Then, the participants were positioned in such a way that the arm was supported on the desk to keep the upper arm at the same level as the heart. The upper arm was uncovered 2 inches above the elbow crease. Cuff placed on the upper arm on the brachial artery. Three blood pressure measurements were taken 3minutes apart in a sitting position. Finally, the mean of the three readings was taken to determine the BP status of the respondents.

Anthropometric measurement was carried out using standard procedures and the calibrated instruments. The participant's weight was measured by PRESTiEGE a portable adult digital weight scale. Weight of the participants was recorded to the nearest $0.1 \mathrm{~kg}$. The participant's height was measured using PRESTiEGE 
a portable Stadiometer. Then the participants were asked to stand on the footplate with back against the Stadiometer, bring the legs together legs are straight, arms are at the sides, and shoulders are relaxed, back of the participants was touch the stadiometer at heels, buttocks, upper back and head. Then, the headpiece lowered until it touches the crown of the head firmly and compressing the hair. It was recorded to the nearest $0.1 \mathrm{~cm}$.

Participant's random and/or fasting blood glucose was measured using Gmate ${ }^{\mathrm{m}}$ voice blood glucose monitoring system with $\mathrm{Gmate}^{\mathrm{TM}}$ glucose test strip. A single used sharp lancet was used to prick the participant's side of non- dominant ring finger after they washed their hands thoroughly. Then sufficient

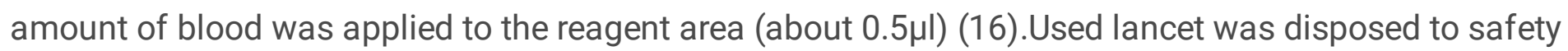
box to prevent cross-contamination. The respondent was declared unavailable if not found on two separate visits.

\section{Data processing and analysis}

Completed questionnaires were coded and entered into Epi Data version 3.1 computer program and SPSS version 23.0 was used for analysis. Data were cleaned and edited by simple frequencies and crosstabulation before analysis. The cleaned final data was then analyzed with SPSS version 23.0.

Regarding the analysis of the outcome variable, Intra-class Correlation Coefficient (ICC) if the item deleted was tested to see intra-observation reliability for both Systolic and Diastolic blood pressure. Then after, the mean score of three blood pressure readings was used to classify the participants' blood pressure. Accordingly, the mean score of systolic blood pressure $\geq 140 \mathrm{mmHg}$ and/or diastolic blood pressure $\geq$ $90 \mathrm{mmHg}$ was coded as 1 and mean systolic blood pressure $<140 \mathrm{mmHg}$ and/diastolic blood pressure $<$ $90 \mathrm{mmHg}$ was coded 0 .

Participant's health-seeking behavior to Hypertension was analyzed from the data collected using a health-seeking behavior questionnaire by calculating the total health-seeking score from 10 items of the health-seeking question with 3 points Likert scale (Yes $=2$, I am not sure $=1$ and $\mathrm{No}=0$ ) was used to calculate health-seeking behavior of adults. Those Adults with the score 11.318 or more were coded 0 and those with lower than 11.318 were coded 1 . BMI of the participant was calculated from the height and weight of the individual.

Participant's knowledge about hypertension was analyzed from data collected using a knowledge questionnaire by calculating the total knowledge score from 20 questions proposed to measure the participant's knowledge about, causes, risk factors, and prevention method of hypertension. Those adults with the score 23.3 or more were coded Zero and those with lower than 23.3 were coded one. The participant's history of chronic illness coded 1 if the response is "Yes" 0 if the response is "No".

Bi-variable logistic regression analyses were done to see the association between each independent variable and the outcome variable. Even though variables with $p$-value $<0.20$ in the bi-variable logistic regression analysis were a candidate for multivariable logistic regression analysis, ranking was done 
based on their p-value to consider them in multivariable logistic regression analysis since there were more variables than expected to be included in multivariable logistic regression. The logistic regression model fitness was checked using Hosmer-Lemeshow and statistics, not significant was declared as a model fitted. Multicollinearity was checked (VIF $<10)$ indicating the non-existence of multicollinearity among the variables in this study. Both crude and adjusted odds ratio along with $95 \% \mathrm{Cl}$ was estimated to measure the strength of association. The level of statistical significance was declared at a p-value of less than 0.05. Tables and figures were used to display the results.

Ethical and Legal consideration- The study was approved by the Ambo University, Medicine, and Health Sciences College Health Research Ethics Review Committee (CHRERC). The permission and support letter was obtained from the Dano district health department. Voluntary informed, written, and signed consent was obtained from all subjects after describing the nature and purpose of the study by the language they can understand. Each enumerators and data collector were given a face Mask and sanitizer during enumeration and data collection period respectively. Each participant washes his or her hand before physical, biochemical measurement and Blood pressure measuring devices were disinfected using $70 \%$ Isopropyl Alcohol to protect them from COVID-19.Those participants, who identified with hypertension, and diabetic mellitus were given advice and linked to the nearby health institution for further investigation and treatment. Health education was given for pre-hypertensive participants.

\section{Results}

- Socio-demographic, personal and, psychosocial characteristics of the study participants.

Out of the total sample size (605), 569 adults were enrolled in the study yielding a response rate of $94.04 \%$. More than half of the study participants $307(54 \%)$ were male. A high proportion of $266(46.7 \%)$ of the respondents were within the age group of $19-33$ years with a mean $( \pm S D)$ age of $37.2( \pm 11.85)$ years and most of $453(79.6 \%)$ the study participants were married. One out of three $212(37.3 \%)$ participants did not attend formal education and more than half $349(61.3 \%)$ of the participants were farmers. Two out of five $227(39.9 \%)$ participants were belonged to the first poorest quintile on Household Wealthy Index (Table 1).

\section{- Participant's behaviour related characteristic}

From the total study participants, $62(10.9 \%)$ had used any tobacco product, among which $38(6.67 \%)$ and $15(2.63 \%)$ were smokers and smokeless tobacco users respectively, while Nine $(1.5 \%)$ of the study participants were using both smoke and smokeless tobacco product before the time of data collection. About one third, 201 (35.3\%) of study participants have consumed any alcohol products in their life years. More than half 110 (54.7\%) of them are current alcohol users. The majority of 187 (93\%) of them were mainly using locally prepared alcohol. Regarding the Khat users, more than one quintile $123(21.6 \%)$ of the study participants were Khat users (Table 2).

- Prevalence of Unscreened hypertension among Adults 
The prevalence of unscreened hypertension in this study was $83(14.6 \%),(95 \% \mathrm{Cl}$ : $11.95 \%, 17.4 \%)$. Out of this, 12(14.5\%) were systolic only hypertension and 71 (85.5\%) were both systolic and diastolic hypertension. Those Adults aged 19-33 years old were 2.5 times more likely to be left unscreened for hypertension [AOR: $2.53,95 \% \mathrm{Cl}:(1.0,6.0)$ ] than those adults who aged $49-65$ years old. Those adults who had a family history of hypertension were 3.01 more likely to have unscreened hypertension [AOR = $3.01,95 \% \mathrm{Cl}:(1.2,7.7)]$ when compared to those who had not. In this study, those adults who had a history of chronic disease were $71.9 \%$ less likely to have unscreened hypertension [AOR $=0.281,95 \% \mathrm{Cl}$ : $(0.11,0.725)]$ when compared to those who had not. Those adults who had low knowledge about the cause, risk factors, and prevention method of hypertension were 2.3 times more likely to have Unscreened hypertension $[A O R=2.23,95 \% \mathrm{Cl}:(1.2,4.5)]$ when compared to those who had good knowledge. The study also revealed that having low health-seeking behavior toward hypertension increases the odds of being Unscreened for hypertension by more than three folds [AOR $=3.3,95 \% \mathrm{Cl}:(1.6,6.55)]$ (Fig. 1)

Table 3: Factor associated with Unscreened hypertension in multi-variable regression among adults living in rural area in Dano district, Central Ethiopia, 2020. $(n=569)$

\section{Discussion}

The prevalence of unscreened hypertension in the study area is $14.6 \%$ [(95\% $\mathrm{Cl}: 11.95 \%, 17.4 \%)]$. In this study, age of the participants, family history of hypertension, having other chronic illness, adults' healthseeking behavior toward hypertension, and adults' knowledge about the causes, risk factors, and prevention methods of hypertension was identified as a factor associated to Unscreened hypertension in the study area.

The prevalence of Unscreened hypertension in this study is comparable with the recent study in India(10.1\%), Nigeria $(14.6 \%)(17,18)$ and other study conducted in Ethiopia country wide $(15.6 \%)$, HawelaTula sub-city $(12.3 \%)$,Gulale,(13.25\%),Hosanna(10.2\%) $(9,10,19,20)$ and it is higher when compared to study done in USA $(6.5 \%)$ and Gilgal-gibe field research $(7.5 \%)(21,22)$. The variation might be due to the difference in screening strategy the country undertaking for the study in the USA and difference in the population studied (i.e. lower age cut-off used as compared to present study) for the Gilgal gibe study. The prevalence of Unscreened hypertension observed in the present study was lower than the prevalence reported by the study conducted in, Nekemte town and Dire Dawa city(23)(24). The variation may be due to the difference in the socio-demographic characteristics of the participant and the difference in population studied.

This study indicated that those Adults aged between 19-33 years old were 2.5 times more likely to have unscreened hypertension when compared to those from 49-65 years. This might be due to that, older adults are more likely to have a higher number of health care visits, which could increase the probability of having diagnosed for hypertension than those aged 19-33 years old. This finding is supported by the studies done in Lebanon $(25,26)$. Whereas the study in Ethiopia showed that respondents with age 40 or above were 2 times more likely to have Unscreened hypertension. The variation may be due to the resent 
protocols and algorithms for detection of hypertension in adults of above 30 years old launched by Federal Minster of health in 2019 (27).

This study found that, those adults with other chronic illness were $71.9 \%$ less likely to have unscreened hypertension when compared to those who had not. This might be due to that the subject with other chronic illness are more likely resulted in more frequent visit and interact with multiple health providers, thus are more likely to be aware of their hypertensive status (28). This finding is in line with a study conducted by the World Health Organization in 6 populous middle-income countries, including China, Ghana, India, Mexico, Russia and South Africa and Lebanon $(25,28,29)$

In this study, adults who have low health-seeking behaviour were 3.3 times more likely to have unscreened hypertension than those of high health-seeking behaviour. The difference may be due to that, those adults with low health-seeking behaviour are less likely to visit the health institution for hypertension screening. This finding is supported by the study conducted in Ethiopia (9).

This study reviled that, those adults having low knowledge about the cause, risk factors and prevention method of hypertension were 2.3 times more likely to have unscreened hypertension when compared with an adult having good knowledge about the causes, risk factors and prevention methods of hypertension. This might be due to the reality that those adults having good knowledge about hypertension are more likely to seek health care and so that they can be diagnosed for hypertension. This finding is in line with the study done in Nigeria and Ethiopia $(29,30)$. This study showed that those adults having a family history of Hypertension were 3.1 more likely to have unscreened hypertension. This might be due to the fact that hypertension tends to run among families(31). This finding is similar to the study done in Ethiopia(9).

\section{Conclusion}

Unscreened hypertension is a considerable public health problem among adults living in the rural of Dano district. The study also demonstrated that being in age 19-33, having a family history of hypertension, having low health-seeking behavior to hypertension, and having low knowledge about the cause, risk factors, and prevention methods of hypertension were associated with increased the odds of Unscreened hypertension whereas, having other chronic illness was associated with reduced the odds of Unscreened hypertension among adults living in the rural area.

\section{Strength and limitation of the study}

The study was unique, as it comprehensively examined the health factors associated with Unscreened hypertension and provided cues for future hypertension prevention programs.

Despite these strength, due to the nature of the study design (Cross-sectional study design), inferring the causality was not possible. Self-reported data (e.g., history of chronic disease \&family history of HTN) might have recall bias. The blood pressure was measured three times in one occasion, which was 
different from the Hypertension Clinical Practice Guidelines recommending $\geq 2$ occasions. Fruit and vegetable consumption was measured based on last 7 days experience, which could be too short to determine the status.

\section{Declarations}

\section{Acknowledgements}

The authors thanks all study participants and all the data collectors and supervisors for that this study would not have been possible without them. They also thank Ambo University and Ministry of Education for arranging the necessary budgets needed for the study.

\section{Conflict of Interest}

The authors declare that there is no any competing interest.

\section{Contribution of Authors}

All the authors were involved in designing the study, analyzing and interpretation of the data, and drafting and writing the paper

\section{References}

\section{References}

1. World health organization. Global Atlas on cardiovascular disease prevention and control. Shanthi Mendis PP and BN, editor. World health organ; 2014.

2. World Health organization. HYPERTENSION:Putting the pressure on the silent killer. In Switzerland,Geneva: IFPMA; 2016. p. 1-5. Available from: http://www.who.int/mediacentre/factsheets/fs310/en/index2.htmlr

3. www.who.int.\%3E... EFactsheet\%3EDetail

4. World Heath Organization. HYPERTENSION: ACT NOW ! [Internet]. Switzerland,Geneva; 2019. Available from:

5. Ethiopian Public Health Institute, Federal Ministry $f$ Health and WHO. Ethiopia Steps Report On Risk Factors For Non-Communicable Diseaes And Prevalence Of Selected Ncds Ethiopia Steps Report On Risk Factors For Chronic Non- Communicable Diseases And. 2016. 2016;(December):1-13.

6. Gaziano TA, Bitton A, Anand S, Weinstein MC. The global cost of nonoptimal blood pressure. 2001;1472-7.

7. Million Herts@. Unscreened Hypertension [Internet]. Atlanta, Georgia 30345 (770) 458-7400: National Association of Chronic Disease Directors; 2018. 1-8 p. Available from: www.chronicdisease.org

8. WHO. Diagnostic Errors,Technical Series on Safer Primary Care. Switzerland,Geneva; 2016. 
9. Wachamo D. Unscreened Hypertension and Associated Factors among Adult Dwellers in Hawela Tula Sub City, Hawassa, Southern Ethiopia : A Community Based Cross-sectional Study. :1-20. Available from: www.researchersquare.com\%3Earticle

10. Getachew F. Prevalence of Unscreened Hypertension and Associated Factors among Residents in Gulele Sub-City, Addis Ababa, Ethiopia. J Community Med Health Educ. 2018;08(01):6-10.

11. Dano destrict. sociodemographic charcteristic of the Dano district, 2019.

12. World Health Organization. The WHO STEP wise approach to non communicabe disease risk factor survillance. World Health Organization; 2017.

13. Asfaw LS, Ayanto SY, Aweke YH. Health-seeking behavior and associated factors among community in Southern Ethiopia:Community based cross-sectional study guided by Health belief model.:1-23.

14. Karen Glanz, Barbara K. Rimer and KV. HEALTH AND HEALTH. 4th ed. Orleans CT, editor. San Francisco: Jossey-Bass; 2008. 45-62 p.

15. Erkoc SB, Isikli B, Metintas S, Kalyoncu C. Hypertension Knowledge-Level Scale (HK-LS): A Study on Development, Validity and Reliability. 2012;1018-29.

16. Coopey S, Coopey S, Mcdonald M. Blood Glucose Monitoring Protocol. 2021;(April 2018):1-18.

17. Undavalli VK, M. P, H. N. Prevalence of Unscreened hypertension: a public health challenge. Int $J$ Community Med Public Heal. 2018;5(4):1366-70.

18. Odili AN, Thijs L, Hara A, Wei F, Ogedengbe JO, Nwegbu MM, et al. Prevalence and Determinants of Masked Hypertension Among Black Nigerians Compared With a Reference Population. 2016;124955.

19. Bekele A, Gelibo T, Amenu K, Getachew T, Defar A, Teklie H, et al. The hidden magnitude of raised blood pressure and elevated blood glucose in Ethiopia: A call for initiating community based NCDs risk factors screening program. Ethiop J Heal Dev. 2017;31(Specialissue1):362-9.

20. Dereje, NebiyuNebiyu Dereje, Alemu Earsido, Ashenafi Abebe LT. Unscreened and diagnosed hypertension in a community setting at Hosanna town: Uncovering the burden. 2019; Available from: www.researchgate.net\%3Epublication\%3E33

21. Park S, Gillespie C, Jason MS, Msph B, Yang Q, Valderrama AL, et al. Modeled state - level estimates of hypertension prevalence and Unscreened hypertension among US adults during $2013-2015$. 2018;(August):1395-410.

22. Birlew T. Risk Factors for Hypertension among Adults. An Analysis of Survey Data on Chronic NonCommunicable Disease at Gilgel Gibe Field Research Center, South West Ethiopia. Sci J Public Heal. 2015;3(2):281.

23. Geleta GT, Cheme MC, Roro EM. Physical, behavioral and sociodemographic determinants of hypertension among the adult population in Nekemte town, western Ethiopia: community based study. BMC Res Notes [Internet]. 2019;12(1):764. Available from: https://doi.org/10.1186/s13104019-4804-0 
24. Roba HS, Beyene AS, Mengesha MM, Ayele BH. Prevalence of Hypertension and Associated Factors in Dire Dawa City, Eastern Ethiopia: A Community-Based Cross-Sectional Study. Int J Hypertens. 2019;2019.

25. Kanj H et. a. Predictors of Unscreened and Uncontrolled Hypertension in the Local Community of Byblos, Lebanon. 2018;

26. Johnson.et.al. Unscreened hypertension among young adults in Lebanon. J Hypertens. 2014;32(1).

27. WHO E. Improving hypertension prevention and control at primary health care level. 2019;

28. Sum $\mathrm{G}$ et.al. Patients with more comorbidities have better detection of chronic conditions, but poorer management and control [Internet]. 2020. Available from: bmcpublichealth.biomedcentral.com\%3Eart.

29. Zhou J. Association between Unscreened Hypertension and Health Factors among Middle-Aged and Elderly Chinese Population. 2019;

30. Gebrihet TA, Mesgna KH, Gebregiorgis YS, Kahsay AB, Weldehaweria NB, Weldu MG. Awareness, treatment, and control of hypertension is low among adults in Aksum town, northern Ethiopia: A sequential quantitative-qualitative study. PLoS One. 2017;12(5):1-16.

31. CDC. Family History and High Blood Pressure*. 2019; Available from:

\section{Tables}

Table 1: Socio-demographic and personal and health-related characteristics of Adults living in the rural area of Dano district, Oromia, Ethiopia, $2020(n=569)$ 


\begin{tabular}{|c|c|c|c|}
\hline Variable & Category & Frequency & Percentage \\
\hline \multirow[t]{2}{*}{ Sex the participant's } & Male & 307 & 54 \\
\hline & Female & 262 & 46 \\
\hline \multirow[t]{3}{*}{ Age of the participant's } & 19-33years & 266 & 46.7 \\
\hline & $34-48$ years & 192 & 33.7 \\
\hline & 49- 65 years & 111 & 19.5 \\
\hline \multirow[t]{4}{*}{ Participant's religion status } & Protestant & 246 & 43.2 \\
\hline & Orthodox & 169 & 29.7 \\
\hline & Muslim & 135 & 23.7 \\
\hline & Waaqeffataa & 19 & 3.3 \\
\hline \multirow[t]{2}{*}{ Participant's ethnicity } & Oromo & 535 & 94 \\
\hline & Amhara & 34 & 6 \\
\hline \multirow[t]{4}{*}{ Participants marital status } & Married & 453 & 79.6 \\
\hline & Never married & 51 & 9.0 \\
\hline & Divorced/separated & 29 & 5.1 \\
\hline & Widowed & 36 & 6.3 \\
\hline \multirow[t]{2}{*}{ Participant's educational level } & No formal education & 212 & 37.3 \\
\hline & Grade 1-4 & 58 & 10.2 \\
\hline \multirow[t]{3}{*}{ Table 1: Continued... } & Grade 5-8 & 146 & 25.7 \\
\hline & Grade $9-12$ & 122 & 21.4 \\
\hline & Diploma and above & 31 & 5.4 \\
\hline \multirow[t]{4}{*}{ Participants current job } & Farmer & 349 & 61.3 \\
\hline & House wife & 111 & 19.5 \\
\hline & Employee & 22 & 3.9 \\
\hline & Student & 87 & 15.3 \\
\hline \multirow{2}{*}{$\begin{array}{l}\text { Traveling time to the nearby health } \\
\text { facility }\end{array}$} & $\geq 30$ minutes & 342 & 60.1 \\
\hline & $<30$ minutes & 227 & 39.9 \\
\hline \multirow[t]{2}{*}{ Family history of hypertension } & Yes & 38 & 6.7 \\
\hline & No & 531 & 93.3 \\
\hline
\end{tabular}




\begin{tabular}{|lllll|}
\hline Participant's history of chronic illness & Yes & 96 & 16.9 \\
\cline { 2 - 4 } & No & 473 & 83.1 \\
\hline $\begin{array}{l}\text { Participant's house hold wealthy } \\
\text { index }\end{array}$ & Poor & 227 & 39.9 \\
\cline { 2 - 4 } & Medium & 144 & 20 \\
\cline { 2 - 4 } & Rich & 228 & 40.1 \\
\hline
\end{tabular}

Table 2: Distribution of behavioral characteristics among Adults living in rural area of Dano district, Oromia, Ethiopia, $2020(n=569)$

\begin{tabular}{|c|c|c|c|}
\hline Variables & Category & Frequency & Percentage \\
\hline \multirow[t]{2}{*}{ Ever used tobacco product } & Yes & 62 & 10.9 \\
\hline & No & 507 & 89.1 \\
\hline \multirow[t]{2}{*}{ Ever consumed alcohol } & Yes & 201 & 35.3 \\
\hline & No & 368 & 64.7 \\
\hline \multirow[t]{2}{*}{ Current alcohol users } & Yes & 110 & 19.3 \\
\hline & No & 459 & 80.7 \\
\hline \multirow[t]{2}{*}{ Favorite alcohol } & Locally prepared & 187 & 32.9 \\
\hline & Fabricated & 14 & 2.5 \\
\hline \multirow[t]{2}{*}{ Khat users } & Yes & 123 & 21.6 \\
\hline & No & 446 & 78.4 \\
\hline
\end{tabular}

Table 3: Factors associated with unscreened hypertension in bi-variable regression among Adults living in rural area in Dano district, Oromia, Ethiopia, 2020. $(n=569)$ 


\begin{tabular}{|c|c|c|c|c|c|}
\hline \multirow[t]{2}{*}{ Associated factor } & \multirow[t]{2}{*}{ Category } & \multicolumn{2}{|c|}{ Unscreened HTN } & \multirow[t]{2}{*}{ COR 95\% Cl } & \multirow{2}{*}{$\begin{array}{l}\text { P- } \\
\text { Value }\end{array}$} \\
\hline & & Yes (\%) & No (\%) & & \\
\hline \multirow[t]{2}{*}{ Sex of participants' } & Male & $49(59)$ & $258(53.1)$ & $1.27(.8,2.0)$ & 0.316 \\
\hline & Female & $34(41)$ & $228(46.9)$ & 1 & \\
\hline \multirow{3}{*}{$\begin{array}{l}\text { Participants age } \\
\text { category }\end{array}$} & $19-33$ & $48(57.8)$ & $218(44.9)$ & $3.27(1.4, \quad 7.47)$ & .005 \\
\hline & $34-48$ & 28(33.7) & 16433.7) & $2.5(1.06,6.0)$ & 0.035 \\
\hline & $49-65$ & $7(8.4)$ & $104(21.4)$ & 1 & \\
\hline \multirow{4}{*}{$\begin{array}{l}\text { Participants religious } \\
\text { status }\end{array}$} & Protestant & $32(38.6)$ & $214(44)$ & 1 & \\
\hline & Orthodox & 23(27.7) & $146(30)$ & $1.054(0.59,1.87)$ & .859 \\
\hline & Muslim & $23(27.7)$ & $112(23)$ & $1.373(0.76,2.46)$ & .286 \\
\hline & Waaqeffataa & $5(6)$ & $14(2.9)$ & $2.388(0.8,8.0)$ & .116 \\
\hline \multirow[t]{5}{*}{$\begin{array}{l}\text { Participants' level of } \\
\text { education }\end{array}$} & $\begin{array}{l}\text { No formal } \\
\text { education }\end{array}$ & $37(44.6)$ & $175(82.5)$ & 1 & \\
\hline & $1-4^{\text {th }}$ & $9(10.8)$ & $49(10)$ & $0.869(0.34,1.92)$ & 0.728 \\
\hline & $5-8^{\text {th }}$ & $21(25.3)$ & $125(25.7)$ & $0.8(.444,1.4)$ & 0.439 \\
\hline & $9-12^{\text {th }}$ & $14(16.9)$ & $108(22.2)$ & $0.6(.317,1.18)$ & 0.14 \\
\hline & Diploma and above & $2(2.4)$ & $29(6)$ & $0.32(0.075,1.42)$ & 0.137 \\
\hline \multirow[t]{5}{*}{ Table 3 continued... } & & & & 1 & \\
\hline & Married & $67(80.7)$ & $386(79.4)$ & & \\
\hline & Never married & $3(3.6)$ & $48(9.5)$ & $0.36(0.9,1.18)$ & 0.094 \\
\hline & Divorced/separated & $4(4.8)$ & $25(5.1)$ & $0.99(.311,2.73)$ & 0.883 \\
\hline & Widowed & $9(10.8)$ & $27(5.6)$ & $1.92(0.86,4.26)$ & 0.109 \\
\hline \multirow{4}{*}{$\begin{array}{l}\text { Participants' current } \\
\text { job }\end{array}$} & Farmer & $57(68.7)$ & $292(60)$ & 1 & \\
\hline & House wife & $17(20.5)$ & $94(19.3)$ & $0.92(.51,1.67)$ & .80 \\
\hline & Gov't employee & $2(2.4)$ & $20(4.1)$ & $0.51(.11,2.25)$ & .376 \\
\hline & Students & $7(8.4)$ & $80(16.5)$ & $0.446(0.197,1.02)$ & 0.56 \\
\hline Family history of HTN & Yes & 10(12) & $28(5.8)$ & $2.24(1.045,4.8)$ & 0.038 \\
\hline
\end{tabular}




\begin{tabular}{|c|c|c|c|c|c|}
\hline & No & 73(88) & $458(94.2)$ & 1 & \\
\hline \multirow{2}{*}{$\begin{array}{l}\text { History of chronic } \\
\text { Illness }\end{array}$} & Yes & $6(6.25)$ & $90(93.75)$ & $0.34(0.15,0.81)$ & 0.015 \\
\hline & No & 77(16.3) & $396(83.7)$ & 1 & \\
\hline \multirow{2}{*}{$\begin{array}{l}\text { Distance to nearby } \\
\text { health facility }\end{array}$} & $\geq 30$ minutes & $44(53)$ & 298(61.3) & $.712(.446,1.137)$ & 0.155 \\
\hline & $<30$ minutes & $39(47)$ & $188(38.7)$ & 1 & \\
\hline \multirow[t]{2}{*}{$\begin{array}{l}\text { Ever use tobacco } \\
\text { product }\end{array}$} & Yes & $23(27.7)$ & $39(8)$ & $4.39(2.45,7.85)$ & $\hat{0} .001$ \\
\hline & No & $60(72.3)$ & $447(92)$ & 1 & \\
\hline \multirow[t]{2}{*}{ Current smoker } & Yes & $7(8.4)$ & $13(2.7)$ & $3.35(1.29,8.667)$ & 0.013 \\
\hline & No & 76(91.6) & $473(97.3)$ & 1 & \\
\hline \multirow[t]{2}{*}{ Current alcohol users } & Yes & 29(34.9) & $81(16.7)$ & $2.68(1.2,4.47)$ & <. 001 \\
\hline & No & $54(16.5)$ & $405(83.3)$ & 1 & \\
\hline \multirow[t]{2}{*}{ Khat users } & Yes & $40(48.2)$ & $83(17.1)$ & $4.5(2.7,7.38)$ & $\hat{0} .001$ \\
\hline & No & $43(51.8)$ & $403(82.9)$ & 1 & \\
\hline \multirow[t]{2}{*}{ Physical activity } & Physically active & 76(91.6) & $458(94.2)$ & 1 & \\
\hline & $\begin{array}{l}\text { Not physically } \\
\text { active }\end{array}$ & $7(8.4)$ & $28(5.8)$ & $0.66(0.280,1.57)$ & 0.352 \\
\hline \multirow[t]{2}{*}{ Eat fruit in last week } & Yes & $55(66.3)$ & $303(62.3)$ & 1 & \\
\hline & No & 28(33.7) & 183(37.7) & $0.843(.516,1.38)$ & 0.495 \\
\hline \multirow{2}{*}{$\begin{array}{l}\text { Eat Vegetables in last } \\
\text { week }\end{array}$} & Yes & $35(42.2)$ & 201(41.4) & 1 & \\
\hline & No & $48(14.4)$ & $285(58.6)$ & $0.967(0.64,1.55)$ & 0.88 \\
\hline \multirow[t]{2}{*}{$\begin{array}{l}\text { Health seeking } \\
\text { behaviour to HTN }\end{array}$} & Low & 69(83.1) & 199(40.9) & $7.1(3.89,12.9)$ & $<.001$ \\
\hline & Good & 14(4.65) & $287(59.1)$ & 1 & \\
\hline \multicolumn{6}{|l|}{ Table 8 continued... } \\
\hline \multirow[t]{2}{*}{ Knowledge status } & Low & $65(78.3)$ & $211(76.4)$ & $4.7(2.1,8.1)$ & $\hat{0.001}$ \\
\hline & Good & 18(21.7) & $275(76.4)$ & 1 & \\
\hline \multirow[t]{2}{*}{ Overweight } & Yes & $4(4.8)$ & $24(4.9)$ & $0.98(0.33,2.9)$ & 0.96 \\
\hline & No & $79(95.2)$ & $462(95.1)$ & 1 & \\
\hline
\end{tabular}




\begin{tabular}{|llllll|} 
Underweight & Yes & $2(2.4)$ & $45(9.3)$ & $0.242(0.05,1.0)$ & 0.053 \\
\cline { 2 - 6 } & No & $81(97.6)$ & $441(90.7)$ & 1 & \\
\hline Hyperglycemia & Yes & $3(3.6)$ & $23(4.7)$ & $0.755(0.22,2.56)$ & 0.653 \\
& No & $80(96.4)$ & $463(95.3)$ & 1 & \\
\hline
\end{tabular}

NB: $\mathrm{COR}=$ Crude odds ratio, $\mathrm{Cl}=$ Confidence interval, $\mathrm{HTN}=$ Hypertension

Table 4: Factor associated with unscreened hypertension in multi-variable regression among adults living in rural area in Dano district, Central Ethiopia, 2020. $(n=569)$

\begin{tabular}{|c|c|c|c|c|c|c|}
\hline \multirow[t]{2}{*}{ Associated factor } & \multirow[t]{2}{*}{ Category } & \multicolumn{2}{|c|}{ Unscreened HTN } & \multirow{2}{*}{$\begin{array}{l}\operatorname{coR}(95 \% \\
\mathrm{Cl})\end{array}$} & \multirow[t]{2}{*}{ AOR 95\% Cl } & \multirow{2}{*}{$\begin{array}{l}\text { P- } \\
\text { Value }\end{array}$} \\
\hline & & Yes (\%) & No (\%) & & & \\
\hline \multirow[t]{3}{*}{$\begin{array}{l}\text { Participants age } \\
\text { category }\end{array}$} & $19-33$ & $48(57.8)$ & $\begin{array}{l}218 \\
(44.9)\end{array}$ & $\begin{array}{l}3.27(1.4 \\
7.47)\end{array}$ & $2.5(1.0,6.0)^{\star}$ & 0.042 \\
\hline & $34-48$ & 28(33.7) & $\begin{array}{l}164 \\
(33.7)\end{array}$ & $\begin{array}{l}2.5(1.06 \\
6.0)\end{array}$ & $1.9(0.75,4.8)$ & 0.174 \\
\hline & $49-65$ & $7(8.4)$ & $104(21.4)$ & 1 & 1 & \\
\hline \multirow[t]{2}{*}{$\begin{array}{l}\text { Family history of } \\
\text { HTN }\end{array}$} & Yes & $10(12)$ & $28(5.8)$ & $\begin{array}{l}2.24(1 \\
4.8)\end{array}$ & $3.1(1.23,7.78)$ * & 0.016 \\
\hline & No & 73(88) & $458(94.2)$ & 1 & 1 & \\
\hline \multirow[t]{2}{*}{$\begin{array}{l}\text { History of chronic } \\
\text { disease }\end{array}$} & Yes & $6(6.25)$ & $90(93.75)$ & $\begin{array}{l}0.34(0.2 \\
0.81)\end{array}$ & $0.281(0.11,0.72) \star$ & 0.008 \\
\hline & No & $77(16.3)$ & 396(83.7) & 1 & 1 & \\
\hline \multirow[t]{2}{*}{$\begin{array}{l}\text { Health seeking } \\
\text { behaviour }\end{array}$} & Low & $69(83.1)$ & 199(40.9) & $\begin{array}{l}7.1(3.89 \\
12.9)\end{array}$ & $3.3(1.6,6.55)^{\star}$ & 0.001 \\
\hline & Good & $14(4.65)$ & $287(59.1)$ & 1 & 1 & \\
\hline \multirow[t]{2}{*}{ Knowledge status } & Low & $65(78.3)$ & $211(76.4)$ & $\begin{array}{l}4.7(2.1 \\
8.1)\end{array}$ & $2.3(1.2,4.5)^{\star}$ & 0.015 \\
\hline & Good & $18(21.7)$ & $275(76.4)$ & 1 & 1 & \\
\hline
\end{tabular}

NB: $A O R=$ Adjusted odds ratio, $C O R=$ Crude odds ratio, $\mathrm{Cl}=$ Confidence interval, $\mathrm{HTN}=$ Hypertension, * statistically significant

Figures 


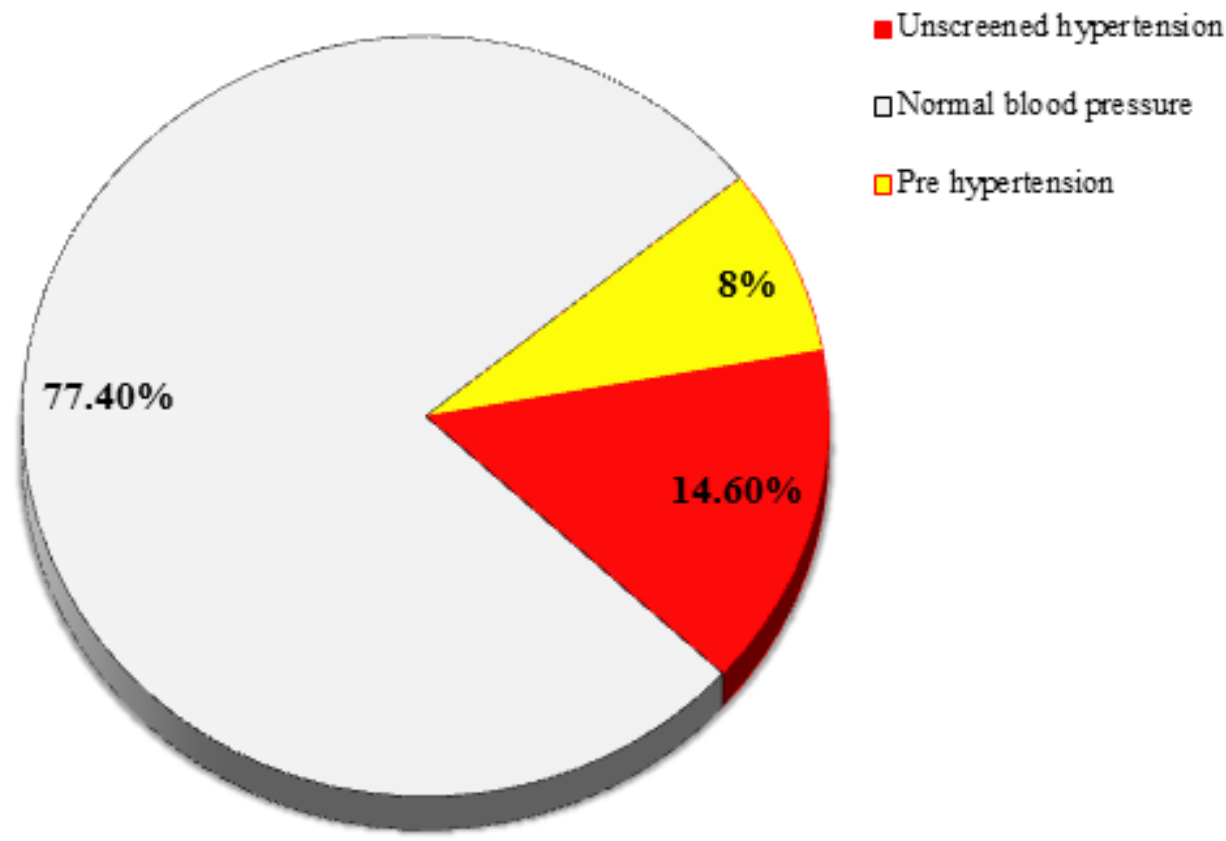

Figure 1

Magnitude of Unscreened hypertension among adults living in Dano District 